\title{
ANALISIS KEJADIAN DISMINORE PADA SISWI WANITA DI SMAN 1 KELEKAR TAHUN 2018
}

\author{
Septiana Rahayu \\ Program Studi Kebidanan, STIK Bina Husada Palembang, \\ Septiana_rahayu@binahuasada.ic.id
}

\begin{abstract}
ABSTRAK
Latar Belakang: Remaja merupakan masa transisi dari anak-anak menjadi dewasa. Menurut World Health Organization (WHO), remaja adalah penduduk dalam rentang usia 10- 19 tahun. Pada masa remaja terdapat perubahan hormonal, fisik, psikologis maupun sosial, dimana kondisi tersebut dinamakan dengan masa pubertas. Salah satu tanda pubertas pada remaja putri yaitu terjadinya menstruasi (Batubara, 2012). Pada saat menstruasi, masalah yang dialami oleh hampir sebagian besar wanita adalah rasa tidak nyaman atau rasa nyeri yang hebat. Hal ini biasa disebut dengan nyeri haid (dismenore) (Putri, 2017). Tujuan dari penelitian: untuk menganalisis kejadian dismenore pada siswi wanita di SMAN 1 Kelekar. Desain penelitian: Jenis penelitian ini adalah observasional analitik dengan rancangan cross sectional dengan pendekatan kuantitatif. Sampel pada penelitian ini adalah keseluruhan populasi 70 siswi. Pemilihan sampel menggunakan total sampling yang berjumlah 70 orang. Penelitian ini dilakukan pada bulan Juni sd Juli 2018. Data dianalisis dengan menggunakan analisis univariat (deskriptif), bivariate (chi square) dan multivariate (regresi logistic). Hasil Penelitian: Dari hasil uji statistik chi square didapatkan variabel yang tidak ada hubungan dengan dismenorea, yaitu usia menarche $(0,599)$, status gizi $(0,847)$, dan variabel yang ada hubungan dengan dismenore, yaitu tingkat kecemasan $(0,001)$, kualitas hidup $(0,001)$. Agar dismenore dapat dihindari diharapkan pada sekolah meningkatkan pengetaahuan siswi dan petugas UKS tentang dismenore malalui penyuluhan, sosialisasi berupa dalam bentuk leaflet dan poster.. Kesimpulan: Agar dismenore dapat dihindari diharapkan pada sekolah meningkatkan pengetaahuan siswi dan petugas UKS tentang dismenore malalui penyuluhan, sosialisasi berupa dalam bentuk leaflet dan poster.
\end{abstract}

\section{Kata Kunci : Usia, Status Gizi, Tingkat Kecemasan, Dismenore.}

\section{ABSTRACT}

Background: Teenagers are a transition from children to adults. According to the World Health Organization (WHO), adolescents are residents in the age range of 10-19 years. In adolescence there are hormonal, physical, psychological and social changes, where the condition is called puberty. One sign of puberty in young women is menstruation (Coal, 2012). During menstruation, the problem experienced by most women is discomfort or extreme pain. This is usually called menstrual pain (dysmenorrhea) (Putri, 2017).. The purposes of this study: This study aims to analyze the incidence of dysmenorrhea in female students at SMAN 1 Kelekar. Research methods This type of research is analytic observational with cross sectional design with quantitative approach. The sample in this study was an overall population of 70 students. The sample selection uses a total sampling of 70 people. This research was conducted from June to July 2018. Data were analyzed using univariate (descriptive), bivariate (chi square) and multivariate (logistic regression) analyzes. The results: From the chi square statistical 
test results obtained variables that have no relationship with dysmenorrhoea, namely the age of menarche (0.599), nutritional status (0.847), and variables that have a relationship with dysmenorrhea, namely the level of anxiety (0.001), quality of life (0.001).. Conclusion: In order to avoid dysmenorrhea, it is hoped that schools will increase the knowledge of students and UKS officers about dysmenorrhea through counseling, socialization in the form of leaflets and posters.

\section{Keywords: Age, Nutrition Status, Anxiety Level, Dysmenorrhea}

\section{PENDAHULUAN}

Beberapa waktu yang lampau masalah remaja dengan alat reproduksinya kurang mendapatkan perhatian karena umur relatief muda, masih dalam status pendidikan sehingga seolah-olah bebas dari kemungkinan menghadapi masalah penyulit dan penyakit yang berkaitan dengan alat reproduksinya (manuaba, 1998)

Remaja merupakan masa transisi dari anak-anak menjadi dewasa. menurut world health organization (who), remaja adalah penduduk dala rentang usia 10-19 tahun. Pada masa remaja terdapat perubahan hormonal, fisik, psikologis maupun social, Dimana kodisi tersebut dinamakan dengan asa pubertas. Saah satu tanda pubertas pada reaja putri yaitu terjadinya menstruasi (batubara, 2012).

Pada saat mentruasi masalah yang dialami oleh hampir sebagian besar wanita adalah rasa tidak nyaman atau rasa nyeri yang hebat. Hal ini biasa disebut dengan nyeri haid (dismenore). Menurut data who, di Indonesia, angka kejadian dismenore sebanyak 55\% dikalangan usia produktif, Dimana 15\% dintaranya mengeluhkan aktivitas menjadi terbatas akibat dismenore (putrid, 2017).

Masa remaja adalah fase pertumbuhan dan perkembangan saat individu mencapai usia 10-19 tahun. Dalam rentang waktu terjadi pertumbuhan fisik yang tepat termasuk pertumbuhan fisik, remaja juga mengalami perubahan jiwa remaja menjadi individu yang sensitif, mudah menangis, mudah cemas, frustasi, tetapi juga mudah tertawa ( tim poltekkes depkes jakarta, 2010).

Periode ini pula wanita-wanita sering mengalai masalah mengenai menstruasi. Masalah yang sering terjadi atau dialami adalah gangguan nyeri menstruasi. Banyak perempuan pada waktu menjelang atau selama menstruasi mengalami kekakuan atau kencang dibagian bawah perut dan kejadian ini demikian disebut dengan istilah dismenore.

Nyeri haid dapat menyerang perempuan yang mengalami haid pada 
usia berapapun. Tidak ada batasan usia dan sering disertai dengan kondisikondisi yang meperberat, seperti pusing, berkeringan dingin, bahkan hingga pingsan .jika sudah seperti ini, tentunya nyeri haid tidak boleh dibiarkan begitu saj nyeri harus diatasi dengan benar (anurgo \& wulandari, 2011).

Penanganan atau penolongan dismenore ini cukup bervariasi mulai dari cara sederhana dengan menggukan kompres air hangat di bagian perut, menggunakan obat-obatan analgeik, cara lain yang dapat dilakukan adalah dengan obat-obatan hormonal, obat-obatan nonsteroid anti prostaglandin (sonya, 2012).

Dismenore terjadi pada wanita dengan tingkat stress rendah sebesar $22 \%$ dengan tingkat stress sedang 29\% dan wanita dengan tingkat stress tinggi ebesar 44\% (sari, p , 2014)

Di Indonesia angka kejadian nyeri menstruasi terdiri dari $44,89 \%$ nyeri menstruasi primer dan $9,36 \%$ nyeri haid sekunder. Biasanya gejala tersebut terjadi pada wanita usia produktif 3-5 tahun setelah mengalai haid pertama daan pada wanita yang belum pernah hail sebanyak $40 \%$ disenore terjadi pada tahun-tahun pertama mendapat menstruasi, $20 \%$ berikutnya pada tahun ketiga dengan kata lain $80 \%$ dismenore terjadi pada 3 tahun pertama setelah seorang wanita mendapat menstruasi. Angka kejadian dismenore di dunia sangat besar. Rata-rata lebih dari 50\% wanita di setiap negara mengalainya. Di amerika serikat angka presentasinya sekitar $60 \%$ dan di swedia sekitar $72 \%$ sementara di Indonesia di perkirakan $55 \%$ wanita usia produktif tersiksa oleh nyeri selama menstruasi angka kejadian dismenore tipe prier di Indonesia adalah sekitar $54,89 \%$ sedangkan sisanya adalah tipe sekunder ( proerawati, 2009).

Angka kejadian nyeri enstruasi (disenore) di dunia sangat besar, ratarata lebih dari $50 \%$ perepuan disetiap negara engalai nyeri ensrtuasi. Di aerka angka presentasinya sekitar $60 \%$ dan di swedia sekitar $72 \%$ seentara di Indonesia angkanya diperkirakan $55 \%$ perepuan usia produktif yang tersiksa noleh nyeri selaa enstruasi. Disenore juga dapat dipengaruhi oleh faktor hormonal, psikis, dan keeasan yang berlebihan. Nyeri enstruasi erupakan suatu gejala dan bukan suatu penyakit. Nyeri enstruasi enajdi dua yaitu nyeri enstruasi enstruasi prier dan sekunder. Nyeri enstruasi yang dijupai tanpa kelainan alat digital yang nyata, sedangkan disenore sekunder disebabkan oleh kelainan ginekologi atau adanya penyakit. 
Berdasarkan penelitian yang dilakukan oleh salsabila alifah putri, 2017 penelitian bertujuan untuk engetahui hubungam antara nyeri haid (dismenore) terhadap aktivitas belajar yang dilakukan oleh siswi kelas I SMP Negeri 52 Jakarta. Didapatkan hasil penelitian menunjukan bahwa terdapat hubungan hubungan signifikan antara nyeri haid (dismenore) dengan aktivitas belajar $(0,000<0,05)$. Kesimpulan dari penelitian ini yaitu terdapat hubungan yang signifikan antar nyeri haid (dienore) dengan aktivitas belajar pada siswi di SMP N 1 Mengalami dismenore dengan rasa nyeri yang mengganggu aktiitas belajar siswi

Berdasarkan studi pendahuluan di SMP N 1 bahwa 7 dari 15 siswa di SMP $\mathrm{N} 1$ mengalami disminore dengan rasa nyeri mengganggu aktifitas belajar siswa

Berdasarkan fenomena diatas, maka penulis tertarik untuk melakukan penelitian tersebut untuk mengetahui hubugan antara keceasan dan respon remaja dengan keparahan dismenore di SMA N 1 Kelekar Muara Enim tahun 2019.

\section{METODE PENELITIAN}

Penelitian ini menggunkan metode purposive sumpling yaitu teknik untuk menentukan sample dengan mengambil secara acak populasi sebagai responden atau sample. (sugiyono, 2013). Jenis penelitian ini menggunakan etode penelitian surey (surey research ethod) yang bersifat surey analitik dengan enggunakan desain potong lintang (ross sectional) untuk elihat bersaa. Pengukuran data yang digunakan adalah kuantitatif karena penelitian ingin mengetahui distribusi frekuensi dalam bentuk angka.

\section{HASIL PENELITIAN}

1. Analisa Univariat

Tabel 1.1

Distribusi Responden Berdasarkan Kualitas hidup dengan kejadian dismenore di SMAN 1 Kelakar Tahun 2018

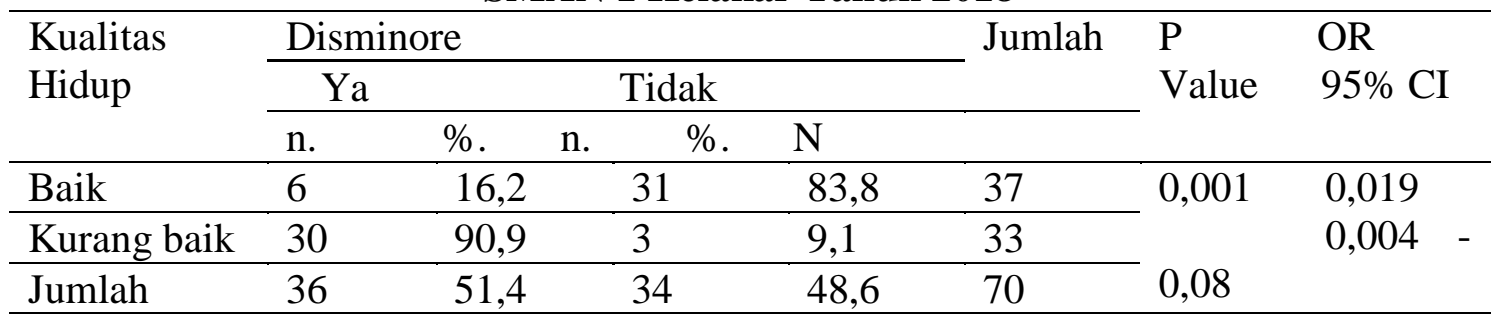


Pada tabel 1.1 menunjukkan bahwa dari 70 responden dengan kualitas hidup katagori baik 6 (16,2 \%). Sedangkan dari 70 responden pada kelompok kualitas hidup kurang baik 30 $(90,9 \%)$ mengalami kejadian dismenore. Hal ini menunjukkan bahwa kejadian dismenore katagori kualitas hidup kurang baik lebih banyak dibandingkan dengan katagori kualitas hidup baik.

Berdasarkan pengujian statistik dengan menggunakan Chi square menunjukkan ada hubungan yang bermakna antara kualitas hidup dengankejadian disminore, dimana $\mathrm{p}$ walue 0,001 lebih keeil dari a-0,05 sching Hipotesis Alternatif (Ha) yang menyatakan ada hubungan antara kualitas hidup dan kejadian dismenore diterima.

Hasil analisis diperoleh nilai odds ratia (OR) sebesar 0,019 (95\% CI. 0,004$0,085)$ artinya responden vang termasuk dalam kelompok ada kualitas hidup baik mempunyai peluang 0,019 kali untuk tidak mengalami dismenore bila dibandingkan responden yang termasuk dalam kelompok kualitas hidup kurang baik.

\section{PEMBAHASAN}

Berdasarkan pengujian statistik dengan menggunakan Chi square menunjukkan tidak ada hubungan yang bermakna antara usia manarche dengan kejadian dismenore dimana $\mathrm{p}$ value $=$ 0,599 lebih besarl dari $\mathrm{a}=0.05$ sehingga Hipotesis Alternatif (Ha) yang menyatakan tidak ada hubungan antara usia manarche dan kejadian dismenore.

Penelitian ini sejalan dengan penelitian vang dilakukan oleh (Sadiman.,2017), analisis faktor yang berhubungan dengan kejadian dismenore, hasil uji statistik dengan uji chi-saquare tidak ada hubungan antara usia menarche dengan kejadian dismenore nilai $\mathrm{p}-0,301$.

Menarche adalah menstruasi pertama yang dialami perempuan (Santrock, 2003). Usia menarche adalah menstruasi pertama yang biasanya terjadi pada perempuan umur 12-13 tahun dalam rentang umur 10-16 tahun (Sukarni, 2013) dalam Sadiman, 2017.

Pada penelitian ini, didapatkan hasil tidak ada hubungan antara usia menarche dengan kejadian dismonore pada siswi SMPN 15 Palembang dikarenakan responden yang berada pada kategori usia manarceh $<12$ tahunn lebih banyak dibandingkan dengan usia $>12$ tahun.

Hubungan Tingkat Kecemasan Dengan Kejadian Dismenore Di SMAN 1 Kelekar Tahun 2018. 
Berdasarkan pengujian statistik dengan menggunakan Chi square menunjukkan ada hubungan yang bermakna antara tingkat kecemasan dengan kejadian dismenore dimana $\mathrm{p}$ value $=0,001$ lebih kecil dari $\mathrm{a}=0,05$ sehingga Hipotesis Alternatif (Ha) yang menyatakan ada hubungan antara tingkat kecemasan dan kejadian Kejadian dismenore diterima.

Penelilitan ini tidak sejalan dengan penelitian oleh (Kusuma., Y.2015), hubungan antara tingkat kecemasan dengan nyeri dismenore primer pada mahasiswi fakultas kedokteran Universitas Islam Indonesia angkatan 2015 statistik menggunakan uji ChiSquare, didapatkan nilai p sebesar 0,152 ( $p>0,05)$ (interval kepercayaan 95\%) artinya bahwa tidak terdapat hubungan yang signifikan antara kecemasan dengan nyeri dismenore pada mahasiswi Fakultas Kedokteran Universitas Islam Indonesia angkatan tahun 2015.

Penelilitan ini sejalan dengan penelitian oleh (Nurwana, Yusuf Sabilu, Andi Faizal Fachlevy.,2017). Analisis faktor yang berhubungan dengan kejadian disminorea pada remaja putri di SMA Negeri 8 Kendari tahun 2016. Berdasarkan hasil uji Exac Fisher Test pada taraf kepercayaan $95 \% \quad(0,05)$ bahwa $\mathrm{p}$ Value $=0,429$, jadi $\mathrm{p}$ Value <a, sehingga HO di terima dan HI di tolak, menunjukkan bahwa tidak terdapat hubungan yang bermakna antara stress dengan kejadian disminore.

Kecemasan merupakan ketegangan, rasa tidak aman dan kekhawatiran yang timbul karena dirasakan terjadi sesuatu yang tidak menyenangkan tetapi sumbernya sebagian besar tidak diketahui dan berasal dari dalam. Kecemasan dapat didefinisikan suatu keadaan rasa gelisah, ketidaktentuan, atau takut dari kenyataan atau persepsi ancaman sumber actual yang tidak diketahui atau dikenal (Hawari,Dadang, 2008 dalam Wuriani, Cau Kim Jiu,2015).

Pada penelitian ini, didapatkan hasil ada hubungan antara tingkat kecemasan dengan kejadian dismonore pada siswi SMPN 15 Palembang dikarenakan responden yang berada pada kategori tidak cemas lebih banyak dibandingkan dengan katagori cemas.

\section{Hubungan Status Gizi Dengan Kejadian Dismenore Di SMAN 1 Kelekar Tahun 2018.}

Berdasarkan pengujian statistik dengan menggunakan Chi square menunjukkan tidak ada hubungan yang bermakna antara status gizi dengan kejadian dismonore dimanap value $=$ 
0,847 lebih besar dari a $=0,05$ sehingga

Hipotesis Alternatif (Ha) yang menyatakan tidak ada hubungan antara status gizi dan kejadian dismenore.

Penelilitan ini sejalan dengan penelitian oleh (Endah Puji Astuti.,2017) Hubungan Indeks Masa Tubuh (IMT) dengan dismenore pada remaja dimana diperoleh Uji analisis didapatkan nilai $\mathrm{p}=0,08$ dan $\mathrm{a}-0,05(\mathrm{p}>0,05)$, artinya tidak ada hubungan IMT dengan dismenore. Remaja yang memiliki IMT normal tetap mengalami dismenore.

Penelilitan ini sejalan dengan penelitian oleh (Nurwana, Yusuf Sabilu, Andi Faizal Fachlevy.2017). Analisis faktor yang berhubungan dengan kejadian dismenore pada remaja putri di SMA Negeri 8 Kendari tahun 2016. Data dianalisis menggunakan uji exact fisher pada tingkat kepercayaan 95\% (a-0,05). Hasil analisis menunjukkan bahwa ada hubungan yang signifikan antara menarche status gizi ( $\mathrm{p}=0,037)$ dengan kejadian dismenore.

Salah satu penilian gizi secara langsung yaitu menggunakan penilaian antropometri dengan pengukuran indeks berat dan tinggi badan merupakansuatu ukuran dari berat badan/BB berdasarkan tingei badan/TB. Sebagai suatu ukuran komposisi tubuh, indeks berat dan tinggi dapat memenuhi kritenia yang diharapkan yaitu mempunyai hubungan erat dengan lemak tubuh dian hubungan yang rendah dengan tinggi badan atau komposisi tubuh (Supaisa. 2012 dalam Endah Puji Astuti.,2017).

Pada penelitian ini, didapatkan hasil tidak ada hubungan antara status gizi dengan kejadian dismenore pada siswi SMPN 15 Palembang dikarenakan responden yang berada pada kategori status gizi katagori baik lebih banyak dengan katagori kurang baik.

\section{Hubungan Kualitas Hidup Dengan Kejadian Dismenore Di SMAN 1 Kelekar Tahun 2018.}

Berdasarkan pengujian statistik dengan menggunakan Chi square menunjukkan ada hubungan yang bermakna antara kualitas hidup dengan kejadian dismenore, dimana $\mathrm{p}$ value $=$ 0,001 lebih kecil dari $\mathrm{a}=0,05$ sehingga Hipotesis Alternatif (Ha) yang menyatakan ada hubungan antara kualitas hidup dan kejadian dismenore diterima.

Peneliti ini sejalan dengan peneliti oleh (Oktavianto.E,Kurniati,F,D ,Badi'ah, A \& Bengu.,M,A,2015), Nyeri dan Kecemasan Berhubungan dengan Kualitas Hidup Remaja Dismenore, Uji analisis yang digunakan untuk melihat hubungan adalah uji korelasi pearson 
terdapat hubungan antara skor kecemasan dan skor nyeri dengan skor kualitas hidup pada remaja selama dismenore ( $\mathrm{p}$ value $<0.05)$.

Kualitas hidup digunakan dalam bidang pelayanan kesehatan untuk menganalisis emosional secorang, faktor sosial, dan kemampuan untuk memenuhi tuntutan kegiatan dalam kehidupan secara normal dan dampak sakit dapat berpotensi untuk menurunkan kualitas hidup terkait kesehatan. (Nursalam, 2013).

Pada penelitian ini, didapatkan hasil ada hubungan antara kualitas hidup dengan kejadian dismenore pada siswi SMAN 1 Kelekar dikarenakan responden yang berada pada kategori kualitas hidup baik lebih banyak dengan katagori kurang baik.

\section{KESIMPULAN DAN SARAN}

\section{Kesimpulan}

Berdasarkan hasil dari penelitian didapatkan bahwa

1. Diketahuinya distribusi frekuensi kejadian disminore $(51,4 \%)$ sedangkan yang tidak dismenore $(48,6 \%)$, responden yang usia menarche $<12$ tanun $(82,9 \%)$, sedangka responden yang $>12$ tahun $(17,1 \%)$, responden dengan tingkat kecemasan katagori cemas $(20,0 \%)$, katagori tidak cemas $(80,0 \%)$. responden status gizi kurang baik $(18,6 \%)$, status gizi baik $(81,4 \%)$, responden kualitas hidup baik $(52,9 \%)$, kurang baik $(47,1 \%)$.

2. Tidak ada hubungan antara usia pertama menarche dengan kejadian dismenore di SMAN 1 Kelekar

3. Ada hubungan antara kecemasan dengan kejadian dismenore di SMAN 1 Kelekar

4. Tidak ada hubungan antara status gizi dengan kejadian dismonore di SMAN 1 Kelekar

5. Ada hubungan antara kualitas hidup dengan kejadian dismenore di SMAN 1 Kelekar

6. Faktor yang dominan dengan kejadian kejadian dismonore pada siswi SMAN 1 Kelekar tahun 2018, yaitu kualitas hidup.

\section{Saran}

\section{Bagi SMAN 1 Kelekar}

Untuk mengatasi terjadihnya dismenore di SMAN 1 Kelekar maka diharapkan pada sekolah meningkatkan pengetahuan siswi dan petugas $\mathrm{UkS}$ tentang dismonore melalui penyuluhan, sosialisasi berupa dalam bentuk leaflet dan poster. Bagi remaja putrid hendaknya lebih meningkatkan cara- cara 
mengatasi nyeri dismenore secara alamiah dan mandiri seperti melakukan kompres hangat dengan botol pada bagian yang kram, tarik nafas dalam secara perlahan untuk relaksasi, latihan olahraga yang teratur dapat menurunkan stress dan kelelahan secara tidak langsung juga mengurangi nyen. Membiasakan olahraga ringan dan aktifitas fisik secara teratur seperti jalan sehat, berlari, bersepeda, ataupun berenang pada saat sebelum dan selama haid, hal tersebut dapat membuat aliran darah pada otot sekitar rahim menjadi lancar, sehingga rasa nyeri dapat teratasi atau berkurang serta lebih aktif lagi dalam mencari informasi mengenai cara-cara mengatasi nyeri mentruasi.

\section{Bagi STIK Bina Husada}

Diharapkan institusi pendidikan Program Studi Pascasarjana Kesehatan Masyarakat STIK Bina Husada dapat bekerjasama dengan tim perpustakaan untuk melengkapi sumber terbaru yang terkait demi kelengkapan Thesis. Khususnya tentang kesehatan reproduksi pada wanita dan remaja.

\section{Bagi Peneliti selanjutnya}

Diharapkan bagi peneliti selanjutnya melakukan penelitian dengan menggali kembali faktorfaktor yang dapat berhubungan dengan kejadian dismonore pada wanita.

\section{DAFTAR PUSTAKA}

1. Affandi, Bari. 2015. Buku Panduan Praktik Pelayanan Kontrasepsi. Jakarta: Bina Pustaka Sarwono Prawirohardjo.

2. Antika, Dita Agil. 2015. Hubungan Penggunaan KB Suntik dengan Siklus Menstruasi Pada Akseptor KB Suntik di Wilayah Kerja Puskesmas Ponjong I Gunung Kidul

Tahun 2014. Naskah Publikasi STIKES Aisyiyah Yogyakarta.

3. Campion, Joan. (2016). KB Suntik Meningkatkan Risiko Kanker Payudara, at http://majalahkesehatan.com/, diakses Oktober 2017.

4. Dahlan, Sopiyudin M. 2016. Statistik Untuk Kedokteran Dan Kesehatan. Jakarta: Salemba Medika.

5. Depkes Kota Palembang. 2016, 2017, 2018. Profil Kesehatan Kota Palembang. Palembang.

6. Dewi, Maria Ulfah Kurnia. 2017. Buku Ajar Kesehatan Reproduksi 
dan Keluarga Berencana Untuk

Mahasiswa Bidan. Jakarta: Trans

Info Media.

7. Uliyah, Mar'atul. 2019. Panduan Aman Dan Sehat Memilih Alat KB. Yogyakarta: Insania.

8. Hani, Ummi dkk. 2018. Asuhan Kebidanan Pada Kehamilan Fisiologis. Jakarta: Salemba Medika.

9. Harini, Ririn. 2017. Perbedaan Pengaruh Pemakaian Kontrasepsi Suntik (Cyclofem dan Depoprogestin) Terhadap Peningkatan Tekanan Darah Pada Wanita Usia Subur Di Wilayah Kerja Puskesmas Pakisaji Malang. Jurnal Keperawatan, ISSN: 2086-3071 Juli 2010.

10. Hidayat, A Aziz Alimul. 2014. Metode Penelitian Kebidanan dan Teknik Analisis

Data Edisi 2. Jakarta : Salemba Medika.

11. Kemenkes RI. 2013, 2014, 2015.Profil Kesehatan Indonesia. Jakarta.

12. Kusmiran, Eny. 2017. Kesehatan Reproduksi Remaja dan Wanita. Jakarta: Salemba Medika.

13. Magas, Maria Magdalena dkk.2016. Perbedaan Siklus Menstruasi Ibu Pengguna Kontrasepsi Suntik Cyclofem Dengan Depo Medroxy
Progesterone Asetat Di Wilayah Kerja Puskesmas Bontang Utara 1. e-jourmal Keperawatan (e-Kp) Volume 4 Nomor 1, Mei 2016.

14. Notoatmodjo, Sockidjo. 2017. Metodologi Penelitian Kesehatan. Jakarta: Rineka Cipta.

15. Pinem, Saroha. 2016. Kesehatan Reproduksi \& Kontrasepsi. Jakarta: Trans Info Media.

16. Pratiwi, Dhania dkk. 2014. Hubungan Antara Penggunaan Kontrasepsi Hormonal Suntik DMPA dengan Peningkatan Berat Badan di Puskesmas Lapai Kota Padang. Jurnal Kesehatan Andalas. 2014; 3(3).

17. Rumende, Inggriany Theresia dkk 2015. Evaluasi Penggunaan Kontrasepsi Suntik Pada Pasangan Usia Subur (PUS) di Kelurahan Walian I tomohon. Pharmacon Jurnal Ilmiah Farmasi-Unsrat Vol. 4 No. 1 Februari 2015 ISSN 2302 - 2493.

18. Sari, Hesti Fajar. 2015. Hubungan Penggunaan Jenis Kontrasepsi Hormonal Dengan

Kejadian Keputihan Pada Akseptor KB di Wilayah Kerja Puskesmas Kartasura

Sukoharjo. Artikel Publikasi Ilmiah Universitas Muhammadyah Surakarta. 
19. Sulistyawati, Ari. 2014. Pelayanan Keluarga Berencana. Jakarta: Salemba Medika.

20. Suratun, dkk. 2018. Pelayanan Keluarga Berencana \& Pelayanan Kontrasepsi. Jakarta: Trans Info Media.

21. Varney, Helen dkk. 2017. Buku Ajar Asuhan Kebidanan Edisi 4 Volume 1. Jakarta:EGC.

22. Wiknjosastro, Hanifa. 2016. Ilmu Kandungan. Jakarta: Bina Pustaka Sarwono Prawirohard 